\title{
KAJIAN PERILAKU PRAGMATIS TERHADAP TINDAK TUTUR SANTRI TERHADAP KYAI DI PONDOK PESANTREN DI WILAYAH KOTA SEMARANG
}

\author{
Oleh: \\ Riris Tiani \\ Fakultas Ilmu Budaya Universitas Diponegoro \\ tiani.riris@gmail.com
}

\begin{abstract}
The main study is speech of moslem students assessed by using pragmatics approach that is politenes principle. Indicator in every maxim of politenes principle is used as santri having (sermon) in front of others santri. The goal of the research is to describe about the implementation of politenes principle maxims and to determine the politenes of santri's speech delivering their sermon to others santri.

The result of data analysis found the applications of tive maxims in Leech politenes principle on santri's speech of the sermon. Its also found the determinant factor of politenes namely linguistics factors and nonlinguistics factors. Linguistics factors was found diction application and style of santri's speech. Meanwhile, nonlinguistics factors was found that senior santri's were more in applicating politenes maxim rather than junior santri's. In addition, the use foreign language such as Arabic.
\end{abstract}

Key words: Politenes Speech, maxim, santri speech, linguistics and nonlinguistics factors

\section{PENDAHULUAN}

Bahasa menunjukkan cerminan pribadi seseorang. Kepribadian, karakter, atau watak seseorang dapat diidentifikasi dari perkataan yang diucapkan. Penggunaan bahasa yang santunmencerminkan pribadi penutur yang berbudi. Upaya untuk menciptakan lingkungan masyarakat yang bertutur santun sangatlah penting karena masyarakat mampu menggunakan bahasa yang benar tetapi dalam bertuturbelum tentu mematuhi prinsip-prinsip kesantunan.

Dalam berkomunikasi, diperlukan kesantunann berbahasa agar terjalin komunikasi yang baik. Komunikasi yang baik terjadi jika penutur dan mitra tutur saling mengerti maksud yang dibicarakan dan informasi yang disampaikan penutur diterima dan dipahami dengan baik.

Kesantunan berbahasa dalam berkomunikasi hendaknya mendapat perhatian. Terkadang penutur bahasa mengungkapkan perasaan dan pemikiran tanpa memperhatikan prinsip kesantunan. Oleh sebab itu,mitra tutur terkadang menemukan pemakaian bahasa yang benar, tetapi nilai rasa yang terkandung dalam tuturan menghina atau menyinggung perasaan mitra tuturnya.

Peristiwa di atas diduga sebagai gejalapenutur bahasa belum mengetahui di dalam suatu struktur bahasa terdapat struktur kesantunan. Struktur bahasa yang santun adalah struktur bahasa yang disusun oleh penutur agar tidak menyinggung perasaan pendengar (Pranowo, 2012 : 4). 
HUMANIKA Vol. 23 No. 2 (2016) ISSN 1412-9418

Kajian Perilaku Pragmatis Terhadap Tindak Tutur Santri Terhadap Kyai Di Pondok Pesantren Di

Wilayah Kota Semarang

Riris Tiani

Ketika berkomunikasi, penggunaan bahasa yang baik belumlah cukup. Seseorang yang mampu berbahasa secara baik berarti sudah mampu menggunakan bahasa sesuai dengan ragam dan situasi. Ketika seseorang berkomukasi dengan orang lain di warung dalam situasi tidak resmi, maka bahasa yang digunakan dalam berkomunikasi berbentuk ragam tidak resmi, seperti bahasa sehari-hari. Begitu juga ketika seseorang sedang berpidato memberikan sambutan dalam rapat sekolah, bahasa yang dipergunakan adalah ragam resmi. Selain itu dalam pengajaran di lembaga pendidikan juga menggunakan ragam resmi seperti sekolah dan pondok pesantren. Kesantunan berbahasa dalam pengajaran juga harus diperhatikan seorang guru saat menyampaikan mata pelajaran.Tidak hanya materi yang disampaikan tetapi nilai kesantunan juga diajarkan untuk mendidik karakter siswa.

Pondok pesantren merupakan lembaga yang mengedepankan pendidikan agama dan pembentukan akhlaq. Di pesantren, pengunaan bahasa ragam tidak resmi dipergunakan santri dalam berkomuniksi sehari-hari dengan santri lain. Dalam situasi resmi seperti kegiatan khitobah penggunaan bahasa harusnya berbeda saat berbicara santai di kamar. Karena khitobah merupakan kegiatan formal penggunaan bahasa disesuaikan dengan situasi formal. Sopan santun santri dalam menyampaikan ceramah merupakan hal yang sangat penting, tidak hanya sopan dalam perilaku tetapi santun dalam bertutur.

\section{RUMUSAN MASALAH}

Bagaimana wujud dan faktor penentu kesantunan tuturan santri terhadap kyai di pondok pesantren di wilayah kota Semarang?

\subsection{Landasan Teori dan Kajian Pustaka}

\subsubsection{Landasan Teori}

Salah satu dari prinsip tersebut adalah prinsip kesantunan atau kesopanan. Dalam buku yang berjudul Berbahasa Secara Santun, Pranowo mengatakan bahasa santun adalah bahasa yang diterima oleh mitra tutur dengan baik (Pranowo, 2012:33).

Teori kesantunan terdapat tiga tokoh yang mengemukakan tentang prinsip kesantunan yaitu Robin Lakoff, Brown dan Levinson, dan Leech. Pada penelitian yang akan dikerjakan menggunakan prinsip kesantunan Leech. Prinsip kesantunan Leech diantaranya maksim kebijaksanaan (tact maxim), maksim kedermawanan (generosity maxim), maksim penghargaan (approbation maxim), maksim kesederhanaan (modesty maxim), maksim permufakatan (Agreement maxim), dan maksim kesimpatian (sympath maxim).

Setiap maksim memiliki ciri-ciri tersendiri yang ditandai dengan bentuk ujuran. Bentuk-bentuk ujuran yang dimaksud adalah bentuk ujuran impositif, komisif, ekspresif, dan asertif. Bentuk ujuran impositif adalah ujuran yang digunakan untuk menyatakan perintah atau suruhan,. Ujaran komisif adalah bentuk ujuran yang berfungsi untuk menyatakan janji atau penawaran. Ujuran ekspresif adalah ujaran yang digunakan menyatakan sikap psikologis pembicara terhadap suatu keadaan. Ujuran asertif adalah ujuran yang lazim digunakan untuk menyatakan kebenaran proposisi yang diungkapkan (Wijana, 1996: 55-56).

Selain Leech, ada pendapat lain yang mengemukakan tentang kesantunan yaitu Brown dan Levinson. Brown dan Levinson (dalam Rustono, 1999:8) berpendapat bahwa kesantunan berbahasa itu berkenaan dengan nosi muka. Nosi muka dibagi menjadi dua, yaitu nosi muka positif dan 
nosi muka negatif. Tuturan dapat mengancam kedua nosi tersebut. Menurut Brown dan Levinson terdapat lima strategi untuk mengurangi atau bahkan menghilangkan ancaman itu, yaitu dengan melakukan tindak tutur: (1) tanpa basa-basi atau ada adanya, (2) menggunakan kesantunan positif, (3) melakukan kesantunan negatif, (4) secara samarsamar, atau (5) diam saja.

Leech (1996:19-22) mengemukakan ada beberapa aspek tuturan yang senantiasa harus dipertimbangkan dalam rangka studi pragmatik. Aspek-aspek tuturan tersebut meliputi penutur dan mitra tutur, konteks tuturan, tujuan tuturan, tuturan sebagai bentuk tindakan / aktivitas, dan tuturan sebagai produk tindak verbal.

Konsep penutur dan mitra tutur adalah meliputi penulis dan pembaca bila tuturan bersangkutan dikomunikasikan dengan media tulisan. Aspek-aspek yang berkaitan dengan penutur dan mitra tutur ini adalah usia, latar belakang sosial ekonomi, jenis kelamin, tingkat keakraban, dan sebagainya.

Konteks tuturan adalah konteks dalam semua aspek fisik atau setting sosial yang relevan dari tuturan bersangkutan. Di dalam pragmatik konteks itu pada hakikatnya adalah semua latar belakang pengetahuan (background knowledge) yang dipahami bersama oleh penutur dan mitra tutur.

Bentuk-bentuk tuturan yang diutarakan oleh penutur dilatar belakangi oleh maksud dan tujuan tertentu. Dalam hubungan ini bentuk - bentuk tuturan yang bermacam-macam dapat digunakan untuk menyatakan maksud yang sama. Atau sebaliknya, berbagai macam maksud dapat diutarakan dengan tuturan yang sama.

\subsubsection{Penelitian yang Relevan}

Ardhiarta, Alfan Alif (2011): Kesantunan Berbahasa Dalam Interaksi Sosial di Pondok Pesantren Darul Ulum Jombang.

Faktor yang melatarbelakangi kesantunan berbahasa yaitu pertama, jarak sosial antara penutur dan petutur, yakni kiai, nyai santri dan ustadz memiliki perbedaan dari segi umur dan latar belakang sosiokultural. Kedua, status sosial antara penutur dan mitra tutur, dalam komunitas pondokpesantren, kiai dianggap sebagai orang yang paling dihormati karena kiai memiliki kedudukan yang paling tinggi dalam struktur pondok pesantren. Karena dalam pondok pesantren status resmi perilaku tertinggi adalah kiai dan nyai. Ketiga, tindak tutur didasarkan atas kedudukan relatif tindak tutur yang satu dengan yang lainnya, berdasarkan peringkat tindak tutur santri kepada kiai, tindak tutur kiai kepada santri memiliki kedudukan yang berbeda. Keempat, adanya sikap tawadlu', hormat dan santun, keyakinan dalam komunitas pondok pesantren yang menganggap bahwa seorang santri bersikap "tawadlu", hormat, dan santun kepada kiai, nyai, ustadz dan pengurus pondok pesantren. Ilmu yang diperoleh akan jauh lebih bermanfaat jika para santri patuh kepada kiai, nyai, ustadz dan pengurus pondok pesantren.

\footnotetext{
Prihantoro (2014): Aplikasi Prinsip Kesantunan Oleh Anak Ketika Berargumen Dengan Orang Tua.

Penelitian ini bertujuan mengungkapkan prinsip kesantunan yang digunakan anak ketika berargumen dengan orang tuanya. Data diperoleh secara purposif pada anak bernama AP yang psikogramnya menunjukan keunggulan dalam ranah logika dan linguistik. Data lisan dikumpulkan dalam rentang waktu satu bulan dengan metode observasi dan difokuskan pada argumentasi AP atas
} 
HUMANIKA Vol. 23 No. 2 (2016) ISSN 1412-9418

Kajian Perilaku Pragmatis Terhadap Tindak Tutur Santri Terhadap Kyai Di Pondok Pesantren Di

Wilayah Kota Semarang

Riris Tiani

penolakan dari permintaanya. Setelah disortir terdapat 124 penolakan dan 97 kali argumentasi. Prosedur analisis data adalah memadankan tuturan penolakan dengan teori kesantunan dari Leech (1993). Dari hasil analisis, lebih dari $80 \%$ argumentasi AP parallel dengan tact maxim. Ini menunjukan bahwa dalam argumentasi persuasifnya, penutur berusaha untuk memaksimalkan keuntungan dan meminimalkan kerugian pada orang lain, tidak dirinya sendiri.

Yusri (2013): Pelanggaran Kesopanan Berbahasa dalam Komunikasi Politik pada Pemilihan Gubernur Sulawesi Selatan tahun 2013.

Penelitian ini bertujuan untuk mendeskripsikan pelanggaran kesopanan berbahasa yang dilakukan oleh calon gubernur Sulawesi Selatan dalam komunikasi politik menjelang pemilihan gubernur 2013 serta faktor- faktornya. Penelitian ini adalah penelitian kualitatif dengan pendekatan pragmatik. Data penelitian ini ialah data tertulis tuturan para calon gubernur Sulawesi Selatan yang tidak sesuai dengan prinsip kesopanan berbahasa. Sumber data adalah media cetak terbesar di Sulawesi Selatan, yakni Harian Fajar dan Tribun Timur yang terbit selama 4 bulan terakhir, yaitu: April, Mei, Juni dan Juli sebelum pemilihan gubernur. Hasil analisis menunjukkan bahwa 1) sebagian besar pelanggaran terjadi pada maksim kesederhanaan dan 2) pelanggaran terjadi karena kandidat lainnya juga melanggar. Tuturan itu berfungsi untuk menanggapi ataupun berusaha menjatuhkan lawan politiknya yang mencoba meningkatkan citranya dengan memuji dirinya sendiri.

\section{METODE PENELITIAN}

Metode analisis data yang digunanakan dalam penelitian ini adalah metode kontekstual dalam kajian pragmatis, dimana data diperhatikan pada tataran konteks situasi pragmatik dengan tindak tutur yang terjadi. Adapun langkah kerja dari penelitian yang dilakukan adalah:

a. Mentranskrip rekaman tindak tutur santri ke dalam bentuk teks.

b. Mengklasifikasikan tuturan santri yang dianggap memiliki prinsip kesantunan sesuai dengan maksimmaksim yang terdapat dalam prinsip kesantunan Leech.

c. Menerapkan analisis yaitu menindaklanjuti pengkajian tuturan santri keterkaitantuturansantridengan kesantunan bahasa dalammaksimmaksimkesantunan. Hal ini untuk melihat sesuai atau tidaknya tuturansantridengan setiap maksim dalam prinsip kesantunan Leech.

d. Menerapkan faktor penentu kesantunan pada maksim yang mempunyai faktor penentu berupa penggunaan diksi dan gaya bahasa dalam tuturan ceramah santri.

\section{PEMBAHASAN}

\subsection{Prinsip Kesantunan}

\subsubsection{Maksim Kebijaksanaan (Tact Maxim)}

Maksim kebijaksanaan menggariskan bahwa penutur hendaknya berpegang pada prinsip untuk selalu mengurangi atau meminimalkan kerugian pihak lain dan menambah atau memaksimalkan keuntungan mitra tutur dalam berkomunikasi. Penutur yang berpegang dan melaksanakan maksim kebijaksanaan akan dapat dikatakan sebagai orang santun.

\section{TUTURAN 1}

Salah satu contoh sedikit, mungkin begini kalau sampeyan sedanten ini jangan malu kalau melakukan hal yang baik atau mungkin hal apa yang baik contoh seperti jama'ah itu kan hal yang 
baik. Pokoknya kamu jangan malu dengan hal baik. Seumpama disuruh jama'ah ya udah tidak usah malu.

Tuturan di atas terlihat khotib telah memaksimalkan keuntungan dan meminimalkan kerugian para santri yang mendengarkan ceramah. Terlihat pada tuturan "sampeyan sedanten ini jangan malu kalau melakukan hal yang baik" dari tuturan tersebut khotib menyuruh atau memeritah para santri putra untuk melakukan hal yang baik.

Tuturan tersebut terdapat kata 'jangan' berarti itu sebuah larangan, tetapi mempunyai maksud memerintah. Pada tuturan tersebut juga terdapat penekanan atau keharusan melakukan perintah yang disampaikan oleh khotib. Terbukti pada tuturan "Pokoknya kamu jangan malu berbuat baik" penekanan perintah ini ditandai dengan adanya kata 'pokoknya' yang mempunyai maksud seharusnya atau mewajibkan. Ujaran tersebut mempunyai maksud agar santri harus tidak malu melakukan seuatu kebaikan. Penggunaan kata sapaan terhadap mitra tuturanya menggunakan bahasa jawa madya yaitu kata 'sampeyan'. Terlihat khotib menghormati para santri yang mendengarkan. Khotib tahu bahwa yang mendengarkan ceramah bukan santri yang lebih muda tetapi ada santri yang lebih tua dari dirinya.

\subsubsection{Maxim Maksim Penghargaan (Approbation Maxim) \\ Maksim penghargaan menjelaskan} bahwa orang akan dapat dianggap santun apabila dalam bertutur selalu memberikan penghargaan kepada orang lain. Dengan maksim ini, diharapkan agar penutur tidak saling mengejek, saling mencaci, atau saling merendahkan pihak lain. Maksim penghargaan menggariskan setiap penutur untuk meminimalkan atau mengurangi cacian terhadap orang lain dan memaksimalkan pujian terhadap orang lain.

\section{TUTURAN 2}

Wah cah iku sing sregep ibadah, imane kuat.

Tuturan tersebut terlihat bahwa khotib telah memaksimalkan pujian dan meminimalkan atau mengurangi cacian terhadap santri. Terlihat pada tuturan "Wah cah iku sing sregep ibadah, imane kuat" yang mana terdapat pujian terhadap mitra tutur. Maksim penghargaan terbukti dengan adanya kata ' $W a h$ ' yang menunjukan atau mengungkapkan rasa kagum terhadap sesuatu. Khotib kagum dengan seseorang yang ibadahnya rajin. Secara tidak langsung khotib telah menerapkan maksim penghargaan saat berceramah. Dengan menggunakan maksim penghargaan penutur dapat menciptakan penghargaan kepada mitra tutur dengan pujian dan sanjungan.

\subsubsection{Maksim Kesederhanaan (Modesty Maxim) \\ Dalam Maksim kesederhanaan atau} kerendahan hati, penutur diharapkan dapat bersikap rendah hati dengan cara meminimalkan atau mengurangi pujian terhadap dirinya sendiri dan memaksimalkan atau menambah cacian pada dirinya. Jika maksim kedermawanan berpusat kepada orang lain, maka maksim kesederhanaan berpusat pada diri sendiri. Orang yang dianggap sombong adalah ketika orang tersebut di dalam aktifitas bertutur selalu memuji dan mengunggulkan diri sendiri.

\section{TUTURAN3}

Sebelume maafe kaleh sampeyan kabeh, bukan berarti saya disini hanya menjadi ketua pondoksewenangwenangmembuat peraturan sendiri kanggeh sampeyan.

Tuturan di atas menunjukan bahwa khotib telah meminimalkan atau mengurangi pujian terhadap dirinya sendiri dan memaksimalkan atau menambah 
HUMANIKA Vol. 23 No. 2 (2016) ISSN 1412-9418

Kajian Perilaku Pragmatis Terhadap Tindak Tutur Santri Terhadap Kyai Di Pondok Pesantren Di

Wilayah Kota Semarang

Riris Tiani

cacian pada dirinya. Terlihat pada tuturan "bukan berarti saya disini hanya ketua pondok sewenang-wenang membuat peraturan sendiri kanggeh sampeyan".Khotib yang menjabat sebagai ketua pondok memberikan sambutan kepada semua santri dalam kegiatan khitobah. Walau khotib mempunyai jabatan sebagai ketua pondok, khotib tetap merendahkan dirinya dihadapan para santri.

Dikarenakan keduduk paling tinggi dalam struktur organisasi pondok adalah pengasuh pondok. Secara tidak langsung khotib juga merendahkan dirinya bahwa ketua pondok itu lebih rendah dibandingkan pengasuh pondok dan pembantu pengasuh.

Tuturan khotib yang membuktikan bahwa khotib telah menerapkan maksim kesederhanaan. Terlihat pada tuturan "bukan berarti saya disini hanya menjadi ketua pondok sewenang-wenang membuat peraturan sendiri kanggeh sampeyan". Khotib menyatakan bahwa ketua pondok tidak mempunyai hak untuk membuat peraturan sendiri untuk diterapkan kepada semua santri.

Ditambah dengan khotib meminta maaf terlebih dahulu kepada semua santri. Serta khotib menggunakan kata sapaan 'sampeyan' yang dalam masyarakat Jawa digunakan untuk orang yang lebih tua daripada penutur. Kata 'sampeyan' yang merupakan kode madya dan kowe yang merupakan kode rendah. Sapaan sampeyan dalam bahasa Jawa digunakan untuk penutur yang berusia lebih tua dari pada mitratutur. Dalam kegiatan khitobah usia mitra tutur ada yang lebih muda dan lebih tua dari penutur jadi khotib menggunakan sapaan sampeyan agar lebih menghormati mitra tuturnya.
1.1.4. Maksim Permufakatan (Agreement Maxim)

Maksim ini disebut dengan maksim kecocokan. Di dalam maksim kecocokan ditekanakan agar para penutur dapat saling membina kecocokan atau kemufakatan saat berkomunikasi. Apabila terdapat pemufakatan atau kecocokan anatar penutur dengan mitra tutur, masing-masing dari mereka dapat dikatan sebagai pribadi yang dapat bersikap santun.

\section{TUTURAN 4}

Eneh apa uwis? Ana cah gede neng kene sing durung apalrukun iman, sapa mau?. Bajal-bajal angger didekte mosok ora isa?. Iya isa aku a (jawab salah satu santri yang mendengarkan ceramah). Bajal tah.

Tuturan di atas menunjukan bahwa khotib dengan santri terjalin kesepakatan atau kecocokan tentang apa yang dibicarakan. Kecocokan tersebut terlihat pada tuturan "Bajal-bajal didekte mosok ora isa? Iya isa aku a (jawab salah satu santri yang mendengarkan ceramah). Tuturan tersebut menunjukan bahwa khotib dengan santri terjalin persetujuan dengan hal yang dibicarakan.

Tuturan khotib dengan santri telah menerapkan maksim permufakatan atau kecocokan. Maksim tersebut ditandai dengan ujaran 'iya isa aku a'yang membuktikan bahwa santri menanggapi pembicaraan khotib. Dengan menerapkan maksim permufakatan komunikasi akan berjalan dengan baik antara penutur dengan mitra tuturnya. 


\subsection{Faktor Penentu Kebahasaan}

\subsubsection{Faktor Kebahasaan}

Ketika penutur sedang bertutur, pemilihan kata atau diksi dan ketepatan penggunaan gaya bahasa merupakan faktor yang sangat penting yang akan membuat tuturan memiliki kadar kesantunan. Kadar kesantunan dapat diukur dengan pemakaian kata apa kata tersebut termasuk kadar santun atau kurang santun. Efek yang ditimbulkan tuturan kepada mitra tutur akan membuat mitra tutur diposisikan sebagai orang yang dihormati. Pada kegiatan ceramah tidak terlepas dari penggunaan diksi atau pemilihan kata. Pemilihan kata yang tepat dapat mencerminkan kepribadian penutur.

\subsubsection{Faktor Nonkebahasaan}

Faktornonkebahasaan yang menjadi penentu kesantunan dalam kegiatan khitobah adalah pranata sosial budaya yang berlaku dalam masyarakat pesantren, topik yang dibicaran dalam kegiatan khitobah sering menyangkut masalah agama seperti tema yang diberikan saat khitobat 'malu sebagian dari iman' dan 'man jadda wajjada'. Selain itu temuan dilapangan, usia dan tingkat pendidikan mempengaruhi kesantunandalambertutur.

\section{SIMPULAN}

Berdasarkan sajian analisis dari bab sebelumnya, ditemukan lima penerapan maksim dalam prinsip kesantunan dalam tuturan khotib yaitu maksim kebijaksanaan, maksim penghargaan, maksim kesederhanaan, maksim permufakatan, dan maksim kesimpatian. Dari kelima maksim tersebut ada maksim yang sering diterapkan atau didominasi oleh khotib dalam menyampaikan ceramah, yaitu maksim kebijaksanaan dan maksim kerendahan hati.

Faktor penentu kesantunan berbahasa dalam penelitian ini meliputi faktor kebahasaan dan nonkebahasaan. Faktor kebahasaan yang menjadi penentu kesantunan berbahasa santri putra dalam kegiatan khitobah yaitu pemakaian diksi yang tepat dan penggunaan gaya bahasa dalam menyampaikan ceramah. Faktor nonkebahasaan yang menjadi penentu kesantunan berbahasa santri putra saat berceramah dalam kegiatan khitobah yaitu usia santri, tingkat pendidikan dan karakter. 
HUMANIKA Vol. 23 No. 2 (2016) ISSN 1412-9418

Kajian Perilaku Pragmatis Terhadap Tindak Tutur Santri Terhadap Kyai Di Pondok Pesantren Di

Wilayah Kota Semarang

Riris Tiani

\section{DAFTAR PUSTAKA}

Leech, Geoffry. 1993. Prinsip-prinsip Pragmatik. Jakarta: Universitas Indonesia.

Nadar, F.X. 2009. Pragmatik dan Penelitian Pragmatik. Yogyakarta: Graha Ilmu

Pranowo, 2012. Berbahasa Secara Santun. Yogyakarta : Pustaka Pelajar.

\section{JURNAL}

Ardhiarta, Alfan Alif. 2011. Kesantunan Berbahasa Dalam Interaksi Sosial Di Pondok Pesantren Darul Ulum Jombang: Suatu Kajian Pragmatik. Jurnal SKRIPTORIUM, Vol. 2 No. 1.

Prihantoro. 2014. Aplikasi Prinsip Kesantunan Oleh Anak Ketika Berargumen Dengan Orang Tua. (Studi Kasus Tindak Persuasi AP
Rustono, 1999. Pokok-pokok Pragmatik. Semarang: CV. IKIP Semarang Press.

Yule, George. 2006. Pragmatik. Yogyakarta: Pustaka Pelajar.

Wijana, Dewa Putu. 1996. Dasar dasar Pragmatik. Yogyakarta : ANDI.

Ketika Permintaannya Ditolak). Jurnal PAROLE Vol. 5, No. 1 April 2015.

Yusri. 2013. Pelanggaran Kesopanan Berbahasa Dalam Komunikasi Politik Pada Pemilihan Gubernur Sulawesi Selatan Tahun2013. Jurnal PAROLE Vol. 5, No. 1 April 2015. 